This is the peer reviewed version of the following article: [Ait Ichou, J., Larivée, N., Eisenberg, M.J., Suissa, K., and Filion, K.B. (2017). The effectiveness and safety of the Impella ventricular assist device for high-risk percutaneous coronary interve

\title{
The Effectiveness and Safety of the Impella Ventricular Assist Device for High-Risk Percutaneous Coronary Interventions: A Systematic Review
}

\author{
Short Title: Systematic Review of Impella \\ Jamal Ait Ichou*, ${ }^{1}$ Natasha Larivée MSc ${ }^{*}$,,3 Mark J. Eisenberg MD, MPH, ${ }^{1,2,3,4}$ \\ Karine Suissa PDt, MSc, ${ }^{2,3}$ Kristian B. Filion PhD ${ }^{1,2,3,5}$ \\ *Denotes contributed equally as first author. \\ ${ }^{1}$ Faculty of Medicine, McGill University, Montreal, Quebec, Canada \\ ${ }^{2}$ Center for Clinical Epidemiology, Lady Davis Institute, Jewish General Hospital, Montreal, \\ Quebec, Canada \\ ${ }^{3}$ Department of Epidemiology, Biostatistics and Occupational Health, McGill University, \\ Montreal, Quebec, Canada \\ ${ }^{4}$ Division of Cardiology, Jewish General Hospital/McGill University, Montreal, Quebec, Canada \\ ${ }^{5}$ Department of Medicine, McGill University, Montreal, Quebec, Canada
}

Word Count: 2,991

Address for Correspondence:

Kristian Filion, PhD FAHA

Assistant Professor

Departments of Medicine and of Epidemiology, Biostatistics, and Occupational Health

McGill University

3755 Cote Ste Catherine, Suite H416.1

Montreal, Quebec H3T 1E2 Canada

Phone: (514) 340-8222 x 28394

Fax: (514) 340-7564

Email: kristian.filion@mcgill.ca

Mr. Ait Ichou was supported by the Mach-Gaensslen Foundation of Canada Student Grant, funded through the McGill University Research Bursary Program. Ms. Larivée was supported by a Masters bursary from the Fonds de Recherche Quebec Santé (Quebec Health Research Fund). Dr. Filion holds a Canadian Institutes of Health Research New Investigator Award. 


\begin{abstract}
Background: Small randomized controlled trials (RCTs) and observational studies have examined the effectiveness and safety of the Impella device, a percutaneous left ventricular assist device, in the setting of high-risk percutaneous coronary intervention (PCI). However, data are sparse, and results are conflicting. Our objective was to evaluate the effectiveness and safety of the Impella device in high-risk patients undergoing PCI via a systematic review of the literature.

Methods: We searched Medline, EMBASE, and the Cochrane Library for RCTs and observational studies that evaluated the Impella device in high-risk patients undergoing PCI. Inclusion was restricted to studies in which $\geq 10$ patients received the Impella device; both uncontrolled and controlled (versus intra-aortic-balloon pump [IABP]) studies were included.

Results: A total of 20 studies (4 RCTs, 2 controlled observational studies, and 14 uncontrolled observational studies; 1,287 patients) were included, with follow-up ranging from 1 to 42 months. The use of Impella resulted in improved procedural and hemodynamic characteristics in controlled and uncontrolled studies. In controlled studies, the 30-day rates of all-cause mortality and MACE were similar across groups. In most uncontrolled studies, the 30-day rates of all-cause mortality were generally low (range: $3.7 \%$ to $10 \%$ ), though rates of MACE were slightly higher (range: 5\% to $20 \%$ ).
\end{abstract}

Conclusion: The Impella device was found to improve procedural and hemodynamic parameters, but only limited randomized data are available regarding clinical outcomes associated with its use. Large, multi-center RCTs are needed to definitively establish the effectiveness of the Impella device among high-risk PCI patients. 
This is the peer reviewed version of the following article: [Ait Ichou, J., Larivée, N., Eisenberg, M.J., Suissa, K., and Filion, K.B. (2017). The effectiveness and safety of the Impella ventricular assist device for high-risk percutaneous coronary interve

\section{INTRODUCTION}

Temporary percutaneous left ventricular assist devices are indicated for patients in cardiogenic shock or those undergoing high-risk percutaneous coronary interventions (PCIs). ${ }^{1}$ Given the incidence of cardiogenic shock among patients with ST-elevation myocardial infarction (STEMI) or non-STEMI, temporary percutaneous left ventricular assist devices may be prophylactically inserted into high-risk PCI patients. ${ }^{1}$

Currently, there exist several available ventricular assist devices, of which three are frequently used in the United States: the intra-aortic balloon pump (IABP), the TandemHeart device, and the Impella device. The IABP has been the most frequently used ventricular assist device since its introduction in the 1960's due to its ease of insertion and use. Despite its favorable procedural characteristics, the IABP is not sufficient for some patients in severe cardiogenic shock and with a systolic aortic pressure that cannot be improved to more than $60 \mathrm{mmHg}$ by vasopressors $^{2}$. Consequently, the TandemHeart was developed in the early 2000's. However, this device is associated with a bigger vascular profile, arterial and venous large cannula and subsequent vascular complications. ${ }^{1,3}$ Recently, the Impella device entered the market, with five models now available (Impella 2.5, Impella CP (or 3.5), Impella RD, Impella LD, and Impella 5.0), each delivering percutaneously an increasing cardiac output. ${ }^{4}$ The most frequently used devices, Impella 2.5 and Impella 5.0, are capable of increasing cardiac output by up to 2.5 and 5.0 $\mathrm{L} / \mathrm{min}$, respectively ${ }^{5-8}$. Impella works by increasing the maximal blood flow by unloading blood from the left ventricle into the ascending aorta, resulting in improved coronary perfusion pressure and end-organ perfusion. ${ }^{5-7}$ In addition to increasing cardiac output, it also decreases myocardial oxygen consumption and pulmonary capillary wedge pressure ${ }^{6}$, potentially reducing the size of a myocardial infarction (MI) and accelerating its recovery. Circulatory support use of Impella in 
high risk PCI patients increases end-diastolic compliance and reduces end-diastolic wall stress by allowing a more effective unloading of the LV compared to IABP. In addition to improving the cardiac output and the coronary perfusion, this results in a decrease in the myocardial workload and metabolic need and reduces infarct size. ${ }^{9-11}$

Several studies have examined the effectiveness and safety of the Impella device ${ }^{5-8,12-27}$. However, many of these studies were small and produced inconclusive results. Therefore, we conducted a systematic review of randomized controlled trials (RCTs) and observational studies to synthesize the currently available evidence on the effectiveness and safety of the Impella device in high-risk patients undergoing PCI.

\section{METHODS}

Our systematic review followed a pre-specified protocol and is reported following the Preferred Reporting Items for Systematic Reviews and Meta-Analyses (PRISMA) guidelines ${ }^{28}$.

\section{Search strategy}

We systematically searched Medline (via Ovid), EMBASE (via Ovid), and the Cochrane Library databases, from inception to February $15^{\text {th }}, 2016$, for RCTs and observational studies that evaluated the Impella device. In all databases, we searched using the term "Impella*" with no restrictions. This search was supplemented by a hand-search of relevant studies, editorials, commentaries, and reviews on this topic.

Two independent reviewers (JA and NL) assessed all potential relevant studies for inclusion. Any publication deemed potentially relevant by either reviewer during title/abstract screening was carried forward to full-text review. Disagreements during full-text review were resolved by consensus or, if necessary, by a third reviewer (KBF).

\section{Study selection}


This is the peer reviewed version of the following article: [Ait Ichou, J., Larivée, N., Eisenberg, M.J., Suissa, K., and Filion, K.B. (2017). The effectiveness and safety of the Impella ventricular assist device for high-risk percutaneous coronary interve

Studies were included if they 1) evaluated the use of the Impella 2.5 or 5.0 devices; 2) were conducted among high-risk patients undergoing PCI; 3) reported any of the following clinical outcomes: all-cause mortality, major adverse cardiac events (MACE), stroke, MI, repeat revascularization, or bleeding complications [including access site hematoma] at 28-30 days or at longer follow-ups; or any of the following angiographic or hemodynamic characteristics: duration of device support, number of lesions treated, cardiac output provided by the Impella device, angiographic success, and mean arterial pressure (MAP) (before support, on support, and after support); and 4) were published in English or French. Controlled studies were restricted to those comparing the Impella device to IABP.

Studies were excluded if the number of participants receiving the Impella device was less than ten. We also excluded cross-sectional studies, reviews and meta-analyses, editorial, commentaries, and letters to the editor. Studies presented as abstracts or conference proceedings were not considered for inclusion as their results are often not final and they contain insufficient information to adequately assess study quality. Finally, basic science studies and those using animal models were also excluded.

\section{Data extraction}

Two independent reviewers (JA and NL) extracted data using a standardized and pilottested data collection form, with discrepancies resolved by consensus or by a third reviewer (KBF). Data extracted included study characteristics (study design, sample size, patient population, country of study, presence of a control group, follow-up duration, number of crossovers, number of patients lost-to-follow-up), demographic characteristics (age and sex), clinical characteristics (prior coronary artery bypass grafting $(\mathrm{CABG})$, prior PCI, prior MI, hypertension, diabetes, smoking, left ventricular ejection fraction (LVEF)), procedural and hemodynamic outcomes 
(duration of support, cardiac output, lesions treated, angiographic success, MAP (before, on, and after support)), clinical outcomes (all-cause mortality, stroke, MI, MACE, and bleeding complications). For RCTs, data were extracted following an intention-to-treat principle, where patients were considered part of the treatment group to which they were randomized, regardless of treatment received. For observational studies, data were extracted based on treatment received.

\section{Quality assessment}

Quality assessment was performed in duplicate using the Cochrane Risk of Bias Tool for $\mathrm{RCTs}^{29}$ and using "A Cochrane Risk of Bias Assessment Tool: A Tool for Non-Randomized Studies of Interventions (ACROBAT-NRSI)" for observational studies. Quality assessment for RCTs was performed by characterizing the sequence generation; allocation concealment; blinding of participants, personnel, and outcome assessors; incomplete outcome data; selective outcome reporting; or other sources of bias in the specific trial. Each domain was assigned a "low", "high", or "uncertain" risk of bias. For observational studies, quality assessed was performed by assessing the bias due to confounding, bias in selection of participants into study, bias in measurement of interventions, bias due to departure from intended interventions, bias due to missing data, bias in measurement of outcomes, and bias in selection of the reported result. Each was assigned a "low", "moderate", "serious", or "critical" risk of bias. All studies were included regardless of their quality.

\section{RESULTS}

\section{Search results}

Our search identified 906 potentially relevant publications (Figure 1). Following the removal of duplicates and the screening of titles and abstracts, 25 publications were retrieved for 
This is the peer reviewed version of the following article: [Ait Ichou, J., Larivée, N., Eisenberg, M.J., Suissa, K., and Filion, K.B. (2017). The effectiveness and safety of the Impella ventricular assist device for high-risk percutaneous coronary interve

full-text review. A total of 20 studies met our inclusion criteria and were included in our systematic review.

\section{Study and patient characteristics}

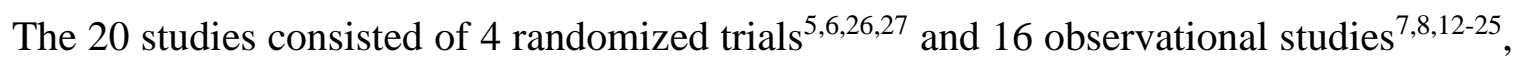
including a total of 1,287 patients (Table 1). All studies were published between 2006 and 2016, and the durations of follow-up ranged from 1 to 42 months. Ten studies examined prophylactic use of the Impella device among high-risk patients undergoing elective PCI, $, 6,12,14,16,18,21,22,24,255$ examined its use among high-risk patients undergoing emergent PCI, 5,8,13,20,26,27 and 4 examined its use in mixed populations of high-risk patients undergoing elective or emergent PCI. ${ }^{15,17,19,23}$ The 4 RCTs contained a total of 438 patients; 1 RCT compared the Impella device to IABP in high-risk patients with left main disease or multi-vessel disease undergoing elective $\mathrm{PCI}^{6}$, while 2 RCTs compared the use of the Impella device and IABP in the setting of emergent PCI in patients with cardiogenic shock and $\mathrm{MI}^{5,27}$. Finally, the IMPRESS in STEMI trial ${ }^{26}$ compared Impella with IABP after primary PCI but was stopped prematurely due to insufficient follow-up. The 15 observational studies included 2 controlled studies that compared Impella with IABP ${ }^{23,24}$ and 13 uncontrolled studies. ${ }^{7,8,12,14-22,25}$

In both controlled and uncontrolled studies, the mean age of patients receiving the Impella device ranged from 57.9 to 79.8 years, and the percentage of male patients ranged from $59.1 \%$ to $100 \%$ (Tables 2 and 3). Mean LVEF was low, ranging from $23 \%$ to 37\%, while the percentage of patients with previous MI was variable, ranging from $24 \%$ to $76 \%$. Overall, patients had multiple co-morbidities and were at high procedural risk. Among comparative studies, patient characteristics were similar between the 2 groups (Table 2).

\section{Quality Assessment}


Three $\mathrm{RCTs}^{5,6,27}$ were deemed to have a low risk of bias, based on the criteria in the Cochrane Risk of Bias tool. However, given the small number of patients randomized in these RCTs, these studies likely had insufficient statistical power to examine clinical outcomes. The IMPRESS in STEMI trial ${ }^{26}$ was deemed to have high risk of bias given its early termination and the widening of inclusion criteria over time ${ }^{26}$. The 2 controlled observational studies ${ }^{23,24}$ were found to both have serious risk of bias due to many methodological limitations, including confounding by indication. All other observational studies were inherently at serious or critical risk of bias due to their uncontrolled nature.

\section{Procedural and hemodynamic characteristics}

The Impella device had favorable procedural characteristics overall (Table 4). The angiographic success rate was high, ranging from 90 to $100 \%$ across studies. The mean duration of support on the Impella device ranged from 38 minutes to 49 hours . The number of lesions treated with the Impella device was fairly consistent, ranging from 1.8 to 3.0 across studies $^{12,14,15,17,18,20,21}$.

The hemodynamic characteristics were also favorable (Table 4). The mean cardiac output provided by the Impella device was consistent across studies (approximately $2.1 \mathrm{~L} / \mathrm{min}$ ). Seven studies reported increases in MAP (before, on, and after support) with the Impella device; however, only 3 of these studies report both pre- and post-procedural MAP. Of these, the study by Dixon et $\mathrm{al}^{21}$ reported lower post-procedural MAP than pre-procedural MAP $(\mathrm{p}=0.004)$ while the Maini et al. registry ${ }^{12}(+6 \mathrm{mmHg} ; \mathrm{p}<0.0001)$ and Seyfarth et al. trial $^{5}(+9 \mathrm{mmHg} ; \mathrm{p}=0.06)$ reported increased MAP post-procedure. The Impella device showed improved procedural and hemodynamic characteristics compared to IABP (Table 4).

\section{All-cause mortality}


This is the peer reviewed version of the following article: [Ait Ichou, J., Larivée, N., Eisenberg, M.J., Suissa, K., and Filion, K.B. (2017). The effectiveness and safety of the Impella ventricular assist device for high-risk percutaneous coronary interve

In controlled studies, the incidence of all-cause mortality among patients using the Impella device was low (Tables 5 and 6). All RCTs found similar rates of all-cause mortality between the Impella device and IABP (Table 5). The trial by O'Neill et al. reported slightly higher rates among patients randomized to the Impella device ( $7.6 \%$ vs. $5.9 \%)$, but this difference was not statistically significant $(\mathrm{p}=0.47)$. The trial by Seyfarth et al. found the 30 -day mortality to be $46 \%$ in both arms $^{5}$, and the IMPRESS trial found 30-day mortality rates of $46 \%$ in the Impella group and 50\% in the IABP group ${ }^{27}$. The much higher mortality rates in these trials relative to other studies are explained differences in study population; these RCTs were conducted in patients with cardiogenic shock or acute MI undergoing emergent PCI.

In the controlled observational studies, the 30-day rates of all-cause mortality were higher in the Impella arm than in the IABP arm in 2 of the 3 studies that reported this endpoint (Table 6). ${ }^{23,24}$ However, neither reached statistical significance due to their modest sample sizes. In most uncontrolled studies, the 30-day rates of all-cause mortality were generally low; ranging from 3.7 to $10 \%{ }^{7,8,12,14-22,25}$ (Table 6). Higher rates were observed in the cohort studies by Engstrom et al. ${ }^{30}$, Henriques et al. ${ }^{22}$, Venugopal et al. ${ }^{15}$, and O’Neill et. al. ${ }^{13}(74 \%, 21 \%, 18 \%$, and $42.6 \%$, respectively), likely due to differences in study population. Engstrom et al. ${ }^{30}$ evaluated the use of the Impella device in high-risk patients undergoing emergent PCI. Although Henriques et al. ${ }^{22}$ evaluated its use in high-risk patients undergoing elective PCI, the study population had a high comorbidity burden (74\% of the patients had previous MI and 53\% had diabetes). Venugopal et al. ${ }^{15}$ evaluated the use of the Impella device in a mixed patient population of elective and emergent that had a mean age of 74 and a mean LVEF of $28 \%$. O'Neill et. al ${ }^{13}$ evaluated the use of Impella in a patient population from the USpella registry that excluded all elective PCIs, leaving emergent PCI with MI complicated by cardiogenic shock. Rates of all-cause mortality were similar to those 
observed with IABP. However, this study did use a composite endpoint of all cause death, MI, stroke, TIA, repeat revascularization, acute renal insufficiency, need for vascular or cardiac operation, severe intraprocedural hypotension requiring therapy, CPR or VT requiring cardioversion, aortic insufficiency and angiographic failure of PCI. Given its heterogeneous components, it is difficult to interpret.

\section{MACE and individual cardiac outcomes}

In controlled studies, the incidence of MACE was low (Table 5). The incidence of MACE and its components was reported by two RCTs (O’Neill et al. ${ }^{6}$; Ouweneel et al. ${ }^{26}$ ). O’Neill et al. reported clinical outcomes for the Impella device and IABP at 30 and 90 days. The only significant difference in cardiac and cerebrovascular events between the two arms was observed for stroke at 30 days ( $0 \%$ with the Impella device vs $1.8 \%$ with IABP, $\mathrm{p}=0.04)$. Although not significant, substantially lower rates of MACE $(40.6 \%$ vs $49.3 \%, \mathrm{p}=0.07)$ and repeat revascularization $(3.6 \%$ vs $7.8 \%, \mathrm{p}=0.06$ ) at 90 days were observed among patients randomized to the Impella device compared with those randomized to the IABP. While numerically lower rates of MI were observed with Impella at 30 and 90 days, these comparisons were not statistically significant due to the limited number of included events. Finally, Ouweneel et al. ${ }^{26}$ reported clinical outcomes for the Impella device and IABP at 90 days and 1 year, however no significant differences were observed (Table 5).

These outcomes were also examined in one controlled observational study (Table 5). Schwartz et al. ${ }^{24}$ reported lower 30-day rates of MACE and MI for Impella patients than in IABP patients. However, with a sample size of only 18 patients (13 patients and 5 IABP), no definitive conclusions can be drawn from these data. Rates of stroke reported by this study were similar across groups. 
This is the peer reviewed version of the following article: [Ait Ichou, J., Larivée, N., Eisenberg, M.J., Suissa, K., and Filion, K.B. (2017). The effectiveness and safety of the Impella ventricular assist device for high-risk percutaneous coronary interve

In the uncontrolled studies, the 30-day rates of MACE (range: 5\% to 20\%) and MI (range: 0 to $63.6 \%$ ) varied greatly across studies (Table 6). This heterogeneity was largely explained by differences in patient population. Rates of stroke (range: $0 \%$ to $2 \%$ ) and repeat revascularization (range: $0 \%$ to $0.6 \%$ ) were low.

\section{Bleeding complications}

Bleeding was not reported in controlled studies. Among uncontrolled studies, access site hematoma rates with the Impella device at 30 days were heterogeneous, with 3 studies reporting rates of approximately $8 \%^{14,17,19}$ and 2 studies reporting substantially higher rates $\left(15.3 \%{ }^{16}\right.$ and $40 \%{ }^{21}$, respectively) (Table 4).

\section{DISCUSSION}

This study was designed to synthesize the available evidence regarding the effectiveness and safety of the Impella device in high-risk patients undergoing PCI. We found limited evidence available, with only 4 small RCTs and 16 observational studies examining its use. Included studies reported promising hemodynamic and procedural characteristics with the Impella device. In addition, the cardiac output provided by the Impella device was approximately $2.1 \mathrm{~L} / \mathrm{min}$, which is higher than that provided by $\mathrm{IABP}^{31}$. No differences in all-cause mortality between the Impella device and the IABP were observed, however, a notable reduction in MACE at 90 days with the Impella device was reported in the RCT by O'Neill et al. (odds ratio vs IABP: 0.79, 95\% CI: 0.640.96). Among uncontrolled studies, the rates of all-cause mortality and adverse events were heterogeneous due to differences in study populations and their underlying cardiovascular risk. Although bleeding parameters were not reported in controlled studies, uncontrolled studies suggest that Impella may results in some bleeding complications. Importantly, most studies were small and 
inadequately powered to assess clinical events, and all observational studies had a high or critical risk of bias.

The Impella device offers many theoretical advantages over traditional cardiac assist devices due to its potential for increased cardiac output, continued function irrespective of timing or trigger, and stability, even in the presence of cardiac conditions such as arrhythmias. The effective unloading of LV provided by the use of Impella clinically benefits patients with severely impaired LV function because it can effectively support the failing circulation and reduce the infarct size in case of $\mathrm{MI}^{10}$. A study by Cohen et. $\mathrm{al}^{32}$ compared the procedural, hemodynamic, and clinical characteristics of patients undergoing high-risk PCI supported by Impella 2.5 in a multicentre registry (USpella) versus a randomized trial (PROTECT II). Compared to RCT participants, registry patients were at higher risk due to their more advanced age and high comorbidity burden. Despite these differences, clinical outcomes were similar across studies. ${ }^{33}$ Currently, the 2015 American College of Cardiology/American Heart Association/Society for Cardiovascular Angiography and Interventions Guidelines for PCI recommend percutaneous mechanical circulatory support in two clinical settings: 1) as an adjunct to high-risk PCI (Class IIb) and 2) for cardiogenic shock in patients presenting with STEMI (Class Ib). ${ }^{34}$ The U.S. Food and Drug Administration (FDA) approved both the Impella 2.5 system and the Impella RP system in 2015.

There remains a need for large, multi-center, RCTs powered to examine the impact of the Impella device on clinical events. With only four small trials completed to date, much of the available evidence comes from observational studies. Although two of the observational studies had a IABP control group, these studies were affected by confounding by indication and by other variables. The other observational studies were greatly limited by the lack of control group, 
This is the peer reviewed version of the following article: [Ait Ichou, J., Larivée, N., Eisenberg, M.J., Suissa, K., and Filion, K.B. (2017). The effectiveness and safety of the Impella ventricular assist device for high-risk percutaneous coronary interve

rendering their results difficult to interpret. Currently, there is one ongoing randomized, multicenter trial examining the Impella device (DanShock NCT01633502). This trial is comparing the Impella 3.5 device to conventional circulatory support in patients with cardiogenic shock complicating AMI. The primary endpoint is 6-month mortality and is expected to enroll a total of 360 patients, although this trial is not being conducted in a high-risk PCI population. ${ }^{35}$ Importantly, the lack of RCTs examining temporary percutaneous left ventricular assist devices is partly attributable to the difficulty in randomizing patients in trials of hemodynamic support. Patients with the greatest need for such support often are not randomized in such trials and are likely to receive the intervention regardless (e.g., due to physician concerns about the outcome, family concerns, etc.). Consequently, such trials typically enrol low to moderate risk patients who are less likely to benefit from the support, greatly limiting the generalizability of the trial results and resulting in potential selection bias. If a composite endpoint is used, it should include clinically important events that are prognostically important. Future trials of Impella and other hemodynamic support must ensure that high-risk patients who are most likely to benefit from such support are included and that composite endpoints only include prognostically important components to better understand the benefits and risks of hemodynamic support among patients undergoing high-risk PCI.

Our study has some potential limitations. First, although we examined the effect of Impella on several outcomes, we did not assess its effect on hemolysis. Second, the individual studies included in our systematic review had small sample sizes and were thus underpowered to detect important differences in clinical events. Third, due to heterogeneity in study designs (e.g., presence of a comparator), study population, and reporting of results, we were unable to pool data across studies via meta-analysis. Fourth, many of the included studies were observational and thus subject 
to biases such as confounding by indication and by other variables. Such biases were considered in our quality assessment. Finally, as is true with all systematic reviews, there is the potential for publication bias.

\section{CONCLUSIONS}

Our study was designed to synthesize the current data regarding the effectiveness and safety of the Impella device among high-risk patients undergoing PCI. We identified that there is

limited evidence available concerning the effect of Impella on clinical events, particularly compared to IABP. Although procedural and hemodynamic results appear promising, there remains a need for large, multi-center RCTs to conclusively assess the effectiveness and safety of Impella.

\section{ACKNOWLEDGEMENTS}

Mr. Ait Ichou was supported by the Mach-Gaensslen Foundation of Canada Student Grant, funded through the McGill University Research Bursary Program. Ms. Larivée was supported by a Masters bursary from the Fonds de Recherche Quebec Santé (Quebec Health Research Fund). Dr. Filion holds a Canadian Institutes of Health Research New Investigator Award.

The authors thank Dr. Bénédicte Lefebvre for her contributions to an early version of this work.

\section{CONFLICTS OF INTEREST}

The authors have no conflicts of interest to report. 
This is the peer reviewed version of the following article: [Ait Ichou, J., Larivée, N., Eisenberg, M.J., Suissa, K., and Filion, K.B. (2017). The effectiveness and safety of the Impella ventricular assist device for high-risk percutaneous coronary interve 


\section{REFERENCES}

1. Martinez CA, Badheka AO, O'Neill WW. Hemodynamic support in high-risk percutaneous coronary interventions and cardiogenic shock. Interventional Cardiology 2012;4:125-36.

2. Tsagalou EP, Anastasiou-Nana MI, Nanas JN. Intra-aortic balloon counterpulsation for the treatment of myocardial infarction complicated by acute severe heart failure. Congestive heart failure (Greenwich, Conn) 2009;15:35-40.

3. Kar B, Adkins LE, Civitello AB, et al. Clinical Experience with the TandemHeart® Percutaneous Ventricular Assist Device. Texas Heart Institute Journal 2006;33:111-5.

4. McCulloch B. Use of the Impella 2.5 in high-risk percutaneous coronary intervention. Critical care nurse 2011;31:e1-16.

5. Seyfarth M, Sibbing D, Bauer I, et al. A randomized clinical trial to evaluate the safety and efficacy of a percutaneous left ventricular assist device versus intra-aortic balloon pumping for treatment of cardiogenic shock caused by myocardial infarction. Journal of the American College of Cardiology 2008;52:1584-8.

6. O'Neill WW, Kleiman NS, Moses J, et al. A prospective, randomized clinical trial of hemodynamic support with Impella 2.5 versus intra-aortic balloon pump in patients undergoing high-risk percutaneous coronary intervention: the PROTECT II study. Circulation 2012;126:1717-27.

7. Sjauw KD, Konorza T, Erbel R, et al. Supported High-Risk Percutaneous Coronary Intervention With the Impella 2.5 Device. The Europella Registry. Journal of the American College of Cardiology 2009;54:2430-4.

8. Engstrom AE, Cocchieri R, Driessen AH, et al. The Impella 2.5 and 5.0 devices for ST-elevation myocardial infarction patients presenting with severe and profound cardiogenic shock: The Academic Medical Center intensive care unit experience. Critical Care Medicine 2011;39:2072-9.

9. Remmelink M, Sjauw KD, Henriques JP, et al. Effects of mechanical left ventricular unloading by Impella on left ventricular dynamics in high-risk and primary percutaneous coronary intervention patients. Catheter Cardiovasc Interv 2010;75:18794.

10. Meyns B, Stolinski J, Leunens V, Verbeken E, Flameng W. Left ventricular support by catheter-mounted axial flow pump reduces infarct size. Journal of the American College of Cardiology 2003;41:1087-95.

11. Valgimigli M, Steendijk P, Sianos G, Onderwater E, Serruys PW. Left ventricular unloading and concomitant total cardiac output increase by the use of percutaneous Impella Recover LP 2.5 assist device during high-risk coronary intervention. Catheter Cardiovasc Interv 2005;65:263-7. 
This is the peer reviewed version of the following article: [Ait Ichou, J., Larivée, N., Eisenberg, M.J., Suissa, K., and Filion, K.B. (2017). The effectiveness and safety of the Impella ventricular assist device for high-risk percutaneous coronary interve

12. Maini B, Naidu SS, Mulukutla S, et al. Real-world use of the Impella 2.5 circulatory support system in complex high-risk percutaneous coronary intervention: The USpella Registry. Catheterization and Cardiovascular Interventions 2012;80:717-25.

13. O'Neill WW, Schreiber T, Wohns DH, et al. The current use of Impella 2.5 in acute myocardial infarction complicated by cardiogenic shock: results from the USpella Registry. Journal of interventional cardiology 2014;27:1-11.

14. Alasnag MA, Gardi DO, Elder M, et al. Use of the Impella 2.5 for prophylactic circulatory support during elective high-risk percutaneous coronary intervention. Cardiovascular Revascularization Medicine 2011;12:299-303.

15. Venugopal V, Spiro J, Zaphiriou A, et al. Percutaneous Mechanical Ventricular Support in Acute Cardiac Care: A UK Quaternary Centre Experience Using 2.5L, 3.8L and 5.0L Impella Catheters. Cardiology and therapy 2014.

16. Iliodromitis KE, Kahlert P, Plicht B, et al. High-risk PCI in acute coronary syndromes with Impella LP 2.5 device support. International Journal of Cardiology 2011;153:5963.

17. Kovacic JC, Nguyen HT, Karajgikar R, Sharma SK, Kini AS. The Impella Recover 2.5 and TandemHeart ventricular assist devices are safe and associated with equivalent clinical outcomes in patients undergoing high-risk percutaneous coronary intervention. Catheter Cardiovasc Interv 2013;82:E28-37.

18. Ferreiro JL, Gomez-Hospital JA, Cequier AR, et al. Use of Impella Recover LP 2.5 in elective high risk percutaneous coronary intervention. International Journal of Cardiology 2010;145:235-7.

19. Anusionwu O, Fischman D, Cheriyath P. The duration of impella 2.5 circulatory support and length of hospital stay of patients undergoing high-risk percutaneous coronary interventions. Cardiology Research 2012;3:154-7.

20. Casassus F, Corre J, Leroux L, et al. The use of impella 2.5 in severe refractory cardiogenic shock complicating an acute myocardial infarction. Journal of Interventional Cardiology 2015;28:41-50.

21. Dixon SR, Henriques JP, Mauri L, et al. A prospective feasibility trial investigating the use of the Impella 2.5 system in patients undergoing high-risk percutaneous coronary intervention (The PROTECT I Trial): initial U.S. experience. Jacc 2009; Cardiovascular interventions. 2:91-6.

22. Henriques JP, Remmelink M, Baan J, Jr., et al. Safety and feasibility of elective highrisk percutaneous coronary intervention procedures with left ventricular support of the Impella Recover LP 2.5. Am J Cardiol 2006;97:990-2. 
23. Boudoulas KD, Pederzolli A, Saini U, et al. Comparison of Impella and intra-aortic balloon pump in high-risk percutaneous coronary intervention: Vascular complications and incidence of bleeding. Acute Cardiac Care 2012;14:120-4.

24. Schwartz BG, Ludeman DJ, Mayeda GS, Kloner RA, Economides C, Burstein S. High-risk percutaneous coronary intervention with the tandemheart and impella devices: A single-center experience. Journal of Invasive Cardiology 2011;23:417-24.

25. Burzotta F, Paloscia L, Trani C, et al. Feasibility and long-term safety of elective Impella-assisted high-risk percutaneous coronary intervention: A pilot two-centre study. Journal of Cardiovascular Medicine 2008;9:1004-10.

26. Ouweneel DM, Engstrom AE, Sjauw KD, et al. Experience from a randomized controlled trial with Impella 2.5 versus IABP in STEMI patients with cardiogenic preshock. Lessons learned from the IMPRESS in STEMI trial. Int J Cardiol 2016;202:894-6.

27. Ouweneel DM, Eriksen E, Sjauw KD, et al. Impella CP Versus Intra-Aortic Balloon Pump in Acute Myocardial Infarction Complicated by Cardiogenic Shock: The IMPRESS trial. Journal of the American College of Cardiology 2016.

28. Moher D, Liberati A, Tetzlaff J, Altman DG. Preferred reporting items for systematic reviews and meta-analyses: the PRISMA statement. BMJ (Clinical research ed) 2009;339:b2535.

29. Higgins JPT, Altman DG, Gøtzsche PC, et al. The Cochrane Collaboration's tool for assessing risk of bias in randomised trials. BMJ (Clinical research ed) 2011;343.

30. Engstrom AE, Cocchieri R, Driessen AH, et al. The Impella 2.5 and 5.0 devices for ST-elevation myocardial infarction patients presenting with severe and profound cardiogenic shock: the Academic Medical Center intensive care unit experience. Critical Care Medicine 2011;39:2072-9.

31. Perera D, Stables R, Thomas M, et al. Elective intra-aortic balloon counterpulsation during high-risk percutaneous coronary intervention: a randomized controlled trial. Jama 2010;304:867-74.

32. Cohen MG, Matthews R, Maini B, et al. Percutaneous left ventricular assist device for high-risk percutaneous coronary interventions: Real-world versus clinical trial experience. American heart journal 2015;170:872-9.

33. Cohen MG, Matthews R, Maini B, et al. Percutaneous left ventricular assist device for high-risk percutaneous coronary interventions: Real-world versus clinical trial experience. American Heart Journal 2015;170:872-9.

34. Rihal CS, Naidu SS, Givertz MM, et al. 2015 SCAI/ACC/HFSA/STS clinical expert consensus statement on the use of percutaneous mechanical circulatory support devices in cardiovascular care (Endorsed by the American Heart Association, the 
This is the peer reviewed version of the following article: [Ait Ichou, J., Larivée, N., Eisenberg, M.J., Suissa, K., and Filion, K.B. (2017). The effectiveness and safety of the Impella ventricular assist device for high-risk percutaneous coronary interve

Cardiological Society of India, and Sociedad Latino Americana de Cardiologia Intervencion; Affirmation of Value by the Canadian Association of Interventional Cardiology - Association Canadienne de Cardiologie d'intervention). Journal of Cardiac Failure 2015;21:499-518.

35. Rigshospitalet D. Danish Cardiogenic Shock Trial (DanShock). Ongoing.

36. PRISMA Flow Diagram Generator. (Accessed March 30, 2016, at http://prisma.thetacollaborative.ca/generator.) 


\section{FIGURE LEGEND}

Figure 1. PRISMA flow diagram of the systematic literature $\operatorname{search}^{36}$.

Figure 1. PRISMA flow diagram of the systematic literature search ${ }^{36}$.

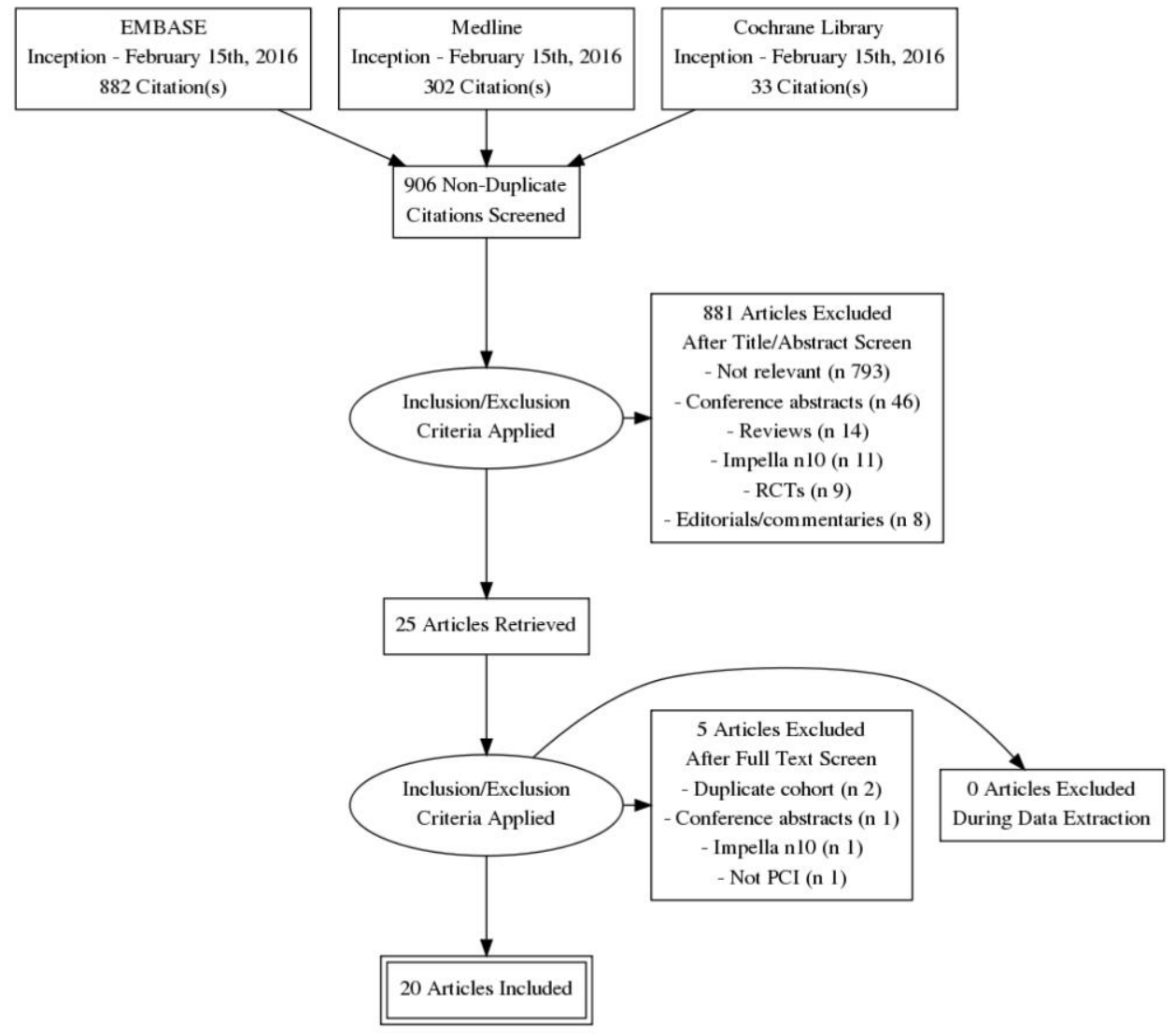


This is the peer reviewed version of the following article: [Ait Ichou, J., Larivée, N., Eisenberg, M.J., Suissa, K., and Filion, K.B. (2017). The effectiveness and safety of the Impella ventricular assist device for high-risk percutaneous coronary interve

Table 1. Characteristics of studies assessing the effectiveness and safety of the Impella device in high-risk patients undergoing PCI.

\begin{tabular}{|c|c|c|c|c|c|}
\hline Study & $\begin{array}{l}\text { Number of } \\
\text { Impella } \\
\text { Patients } \\
\end{array}$ & High-risk Patient Population & Country & $\begin{array}{l}\text { Controlled Study } \\
\text { (Number of } \\
\text { IABP Patients) }\end{array}$ & Follow-ups \\
\hline \multicolumn{6}{|c|}{ Randomized Controlled Trials } \\
\hline O’Neill 2012 [PROTECT II] & 225 & Elective; low LVEF & $\begin{array}{l}\text { USA, Canada, } \\
\text { Europe }\end{array}$ & Yes $(n=223)$ & 30 days, 3 months \\
\hline $\begin{array}{l}\text { Ouweneel } 2016 \text { [IMPRESS } \\
\text { trial] }\end{array}$ & 24 & $\begin{array}{l}\text { Emergent; Severe cardiogenic shock } \\
\text { complicating AMI }\end{array}$ & Amsterdam & Yes $(n=24)$ & 6 months \\
\hline $\begin{array}{l}\text { Ouweneel } 2016 \text { [IMPRESS } \\
\text { in STEMI] }\end{array}$ & 12 & $\begin{array}{l}\text { Emergent; Cardiogenic pre-shock after } \\
\text { AMI }\end{array}$ & International & Yes $(n=9)$ & 42 months* \\
\hline $\begin{array}{l}\text { Seyfarth } 2008 \text { [ISAR- } \\
\text { SHOCK] }\end{array}$ & 13 & Emergent $\mathrm{PCl} ; \mathrm{AMI}$ and $\mathrm{CS}$ & Germany & Yes $(n=13)$ & 30 days \\
\hline \multicolumn{6}{|l|}{ Observational Studies } \\
\hline $\begin{array}{l}\text { Maini } 2012 \text { [USpella } \\
\text { registry] }\end{array}$ & 175 & Elective & USA & No & $\begin{array}{l}30 \text { days, } 6 \text { and } 12 \\
\text { months }\end{array}$ \\
\hline Sjauw 2009 [Europella] & 144 & Elective & Europe & No & 30 days \\
\hline O'Neill 2014 & 63 & Emergent $\mathrm{PCl} ; \mathrm{AMI}$ and $\mathrm{CS}$ & USA & No & 30 days \\
\hline Alasnag 2011 & 60 & Elective; non-surgical & USA & No & 30 days \\
\hline Venugopal 2014 & 45 & Not specified ${ }^{\ddagger}$ & UK & No & 30 days \\
\hline Iliodromitis 2011 & 38 & Elective; non-surgical & Germany & No & 30 days \\
\hline Kovacic $2013^{\S}$ & 36 & Not specified"l & USA & No & 30 days \\
\hline Engstrom 2011 П & 34 & Emergent PCl; CS; Impella 2.5 and 5.0 & Netherlands & No & 30 days \\
\hline Ferreiro 2010 & 27 & Elective & USA & No & 30 days \\
\hline Anusionwu 2012 & 25 & Not specified & USA & No & NR \\
\hline Casassus 2015 & 22 & Emergent $\mathrm{PCl}$; $\mathrm{AMI}$ and $\mathrm{CS}$ & France & No & 6 and 12 months \\
\hline Dixon 2009 [PROTECT I] & 20 & Elective; LVEF $\leq 35 \%$ & USA, Netherlands & No & 30 days \\
\hline Henriques 2006 & 19 & Elective & Netherlands & No & NR \\
\hline Boudoulas 2012 & 13 & Not specified & USA & Yes $(n=62)$ & 1 year \\
\hline Schwartz 2011 & 13 & Elective & USA & Yes $(n=5)$ & 30 days \\
\hline Burzotta 2008 & 10 & Elective & Italia & No & 1 year \\
\hline
\end{tabular}

Abbreviations: PCI: percutaneous coronary intervention, IABP: Intra-aortic balloon pump, LVEF: left ventricular ejection fraction, AMI acute myocardial infarction, CS: cardiogenic shock, NR: not reported

* Trial stopped prematurely due to insufficient recruitment.

${ }^{\dagger}$ Although Maini et. al and O'Neill et. al both reported data from the USpella registry, Maini excluded patients who received emergent PCI for STEMI or CS.

O’Neill restricted inclusion to such patients. 
$\$ 3$ patients had cardiogenic shock in the Impella group

$\S$ This controlled study compared the Impella Recover 2.5 with TandemHeart.

" Patients with acute ST segment elevation or cardiogenic shock were excluded from this study.

II This study compared high-risk patients undergoing PCI using of Impella 2.5 with high-risk patients undergoing PCI using Impella 5.0. 
This is the peer reviewed version of the following article: [Ait Ichou, J., Larivée, N., Eisenberg, M.J., Suissa, K., and Filion, K.B. (2017). The effectiveness and safety of the Impella ventricular assist device for high-risk percutaneous coronary interve

Table 2. Baseline demographic and clinical characteristics of high-risk patients undergoing PCI in controlled studies of the Impella device.

\begin{tabular}{|c|c|c|c|c|c|c|c|c|c|c|c|c|c|c|c|c|c|c|}
\hline \multirow[t]{2}{*}{ Study } & \multicolumn{2}{|l|}{$\mathbf{N}$} & \multicolumn{2}{|l|}{$\begin{array}{l}\text { Age } \\
\text { mean (SD) }\end{array}$} & \multicolumn{2}{|c|}{ Male (\%) } & \multicolumn{2}{|c|}{ Prior CABG (\%) } & \multicolumn{2}{|c|}{ Prior MI (\%) } & \multicolumn{2}{|c|}{$\begin{array}{l}\text { Hyper-tension } \\
\text { (\%) }\end{array}$} & \multicolumn{2}{|c|}{ Diabetes (\%) } & \multicolumn{2}{|c|}{ Smoking (\%) } & \multicolumn{2}{|l|}{ LVEF (\%) } \\
\hline & Imp & IABP & Imp & IABP & Imp & IABP & Imp & IABP & Imp & IABP & Imp & IABP & Imp & IABP & Imp & IABP & Imp & IABP \\
\hline \multicolumn{19}{|c|}{ Randomized Controlled Trials } \\
\hline $\mathrm{O}^{\prime} \mathrm{Neill} 2012$ & 225 & 223 & $68(11)$ & $67(11)$ & 80 & 81.2 & 38.2 & 28.7 & - & - & - & - & 52 & 50.7 & - & - & 23.4 & 24.1 \\
\hline $\begin{array}{l}\text { Ouweneel } \\
2016\end{array}$ & 24 & 24 & $58(9)$ & $59(11)$ & 75 & 83 & - & - & 5 & 4 & 20 & 29 & 9 & 13 & 61 & 32 & - & - \\
\hline $\begin{array}{l}\text { Ouweneel } \\
2016 \\
\text { [STEMI] }\end{array}$ & 12 & 9 & $57(13)$ & $63(13)$ & 75 & 100 & - & - & 8 & 22 & * & 44 & 25 & 0 & 64 & 44 & $\begin{array}{l}39.5 \\
(7.7)^{+}\end{array}$ & $\begin{array}{l}41.4(14) \\
+\end{array}$ \\
\hline $\begin{array}{l}\text { Seyfarth } \\
2008\end{array}$ & 13 & 13 & 65 & 67 & 62 & 85 & - & - & 54 & 62 & 54 & 69 & 39 & 23 & 62 & 54 & - & - \\
\hline \multicolumn{19}{|c|}{ Observational Studies } \\
\hline $\begin{array}{l}\text { Boudoulas } \\
2012\end{array}$ & 13 & 62 & $62.5(9.7)$ & $60.8(12.6)$ & 69.2 & 71 & - & - & - & - & - & - & - & - & - & - & $24(10)$ & $30(15)$ \\
\hline $\begin{array}{l}\text { Schwartz } \\
2011\end{array}$ & 13 & 5 & $79.8(6.7)$ & $70.4(9.0)$ & 62 & 80 & 23 & 20 & 54 & 0 & 100 & 60 & 54 & 60 & 0 & 20 & $31(17)$ & $37(15)$ \\
\hline
\end{tabular}

Abbreviations: Imp: Impella; IABP: Intra-aortic balloon pump; CABG: Coronary artery bypass grafting; LVEF: Left ventricular ejection fraction; MI: Myocardial infarction; PCI: Percutaneous, coronary intervention; SD: Standard deviation.

* Typographical error in supplemental material indicates 23/12 (5) for this value.

${ }^{\dagger}$ LVEF measured in 15 patients (7 Impella and 8 IABP). 
Table 3. Baseline demographic and clinical characteristics of high-risk patients using the Impella device while undergoing PCI in uncontrolled studies of the Impella device.

\begin{tabular}{|c|c|c|c|c|c|c|c|c|c|c|c|}
\hline Study & $\mathbf{N}$ & $\begin{array}{l}\text { Age, } \\
\text { Mean (SD) }\end{array}$ & $\begin{array}{l}\text { Male } \\
(\%)\end{array}$ & $\begin{array}{l}\text { Prior } \\
\text { CABG } \\
(\%)\end{array}$ & $\begin{array}{l}\text { Prior PCl } \\
(\%)\end{array}$ & $\begin{array}{l}\text { Prior } \\
\text { MI (\%) }\end{array}$ & $\begin{array}{l}\text { Hyper- } \\
\text { Tension } \\
(\%)\end{array}$ & $\begin{array}{l}\text { Diabetes } \\
\text { (\%) }\end{array}$ & $\begin{array}{l}\text { Smoking } \\
(\%)\end{array}$ & LVEF (\%) & Crossovers (\%) \\
\hline Maini 2012 & 175 & $70(10)$ & 74 & 28 & 48 & 56 & - & 47 & - & $31(17)$ & - \\
\hline Sjauw 2009 & 144 & $71.8(9.9)$ & 81.3 & 29.2 & - & 52.8 & 67.4 & 43.1 & 42.4 & - & - \\
\hline O’Neill 2014 & 63 & $66(12)$ & 73 & 19.4 & 37.1 & - & 82.3 & 56.7 & - & $25.6(12.9)$ & - \\
\hline Alasnag 2011 & 60 & $68(11)$ & 68 & 18 & 62 & 62 & 95 & 52 & - & $23(15)$ & - \\
\hline Venugopal 2014 & 45 & $74(11)$ & 78 & 7 & 16 & 49 & 82 & 36 & 58 & $28(14)$ & - \\
\hline Iliodromitis 2011 & 38 & $69.7(10.2)$ & 79 & 34 & - & - & 79 & 32 & 47 & - & - \\
\hline Kovacic 2013 & 36 & $71.9(12.2)$ & 69 & 25 & - & - & 92 & 47 & 11 & $26.9(6)$ & - \\
\hline Ferreiro 2010 & 27 & $68.2(9.3)$ & 85.2 & 7.4 & 25.9 & 44.4 & 74.1 & 51.9 & 67.9 & - & $1^{\ddagger}$ \\
\hline Anusionwu 2012 & 25 & $68(9.5)$ & 76 & 36 & 28 & 76 & 92 & 72 & 60 & $32(16)$ & - \\
\hline Engstrom 2011 & 25 & - & 85 & - & - & 24 & 29 & 8.8 & 26 & - & $11^{+}$ \\
\hline Casasssus 2015 & 22 & $57.9(11.6)$ & 59.1 & 4.5 & 31.8 & 31.8 & 54.5 & 18.2 & 55 & $26.6(8.0)$ & $3 *$ \\
\hline Dixon 2009 & 20 & $60(12)$ & 85 & 40 & 45 & 60 & 50 & 45 & 40 & $26(6)$ & - \\
\hline Heniques 2006 & 19 & - & - & - & - & 74 & - & 53 & - & - & - \\
\hline Burzotta 2008 & 10 & $63.5(9.1)$ & 100 & 20 & 20 & 70 & - & 50 & - & - & - \\
\hline
\end{tabular}

Abbreviations: Imp: Impella; IABP: Intra-aortic balloon pump; CABG: Coronary artery bypass grafting; LVEF: Left ventricular ejection fraction; MI: Myocardial infarction; PCI: Percutaneous, coronary intervention; SD: Standard deviation.

* A total of 2 patients were transitioned to Impella 5.0 or extracorporeal membrane oxygenation after the procedure, and 1 patient was transitioned to a long-term left ventricular assist device.

${ }^{\dagger}$ A total of 11 patients were upgraded from Impella 2.5 to Impella 5.0 within 30 days post-procedure.

$\star$ One patient received an IABP due to a malfunction of the Impella device during the procedure. 
This is the peer reviewed version of the following article: [Ait Ichou, J., Larivée, N., Eisenberg, M.J., Suissa, K., and Filion, K.B. (2017). The effectiveness and safety of the Impella ventricular assist device for high-risk percutaneous coronary interve

Table 4. Procedural and hemodynamic characteristics for high-risk patients undergoing PCI and using the Impella device

\begin{tabular}{|c|c|c|c|c|c|c|c|}
\hline \multirow[b]{2}{*}{ Study } & \multirow[b]{2}{*}{$\begin{array}{l}\text { Angiographic } \\
\text { success (\%) }\end{array}$} & \multirow{2}{*}{$\begin{array}{l}\text { Duration of } \\
\text { support, } \\
\text { mean (SD) } \\
\text { (min) }\end{array}$} & \multirow{2}{*}{$\begin{array}{l}\text { Lesions } \\
\text { Treated, } \\
\text { mean (SD) }\end{array}$} & \multirow{2}{*}{$\begin{array}{l}\text { Cardiac output } \\
\text { (SD) } \\
\text { (L/min) }\end{array}$} & \multicolumn{3}{|c|}{ Mean arterial pressure, mean (SD) $(\mathrm{mmHg})$} \\
\hline & & & & & Before support & On support & After support \\
\hline \multicolumn{8}{|c|}{ Randomized controlled trails } \\
\hline O'Neill 2012 & - & $114(162)$ & $2.9(1.4)$ & - & - & - & - \\
\hline Ouweneel 2016 & - & $2940(1680-4560)$ & - & - & $66(15$ & $?$ & ? \\
\hline $\begin{array}{l}\text { Ouweneel } 2016 \\
\text { [STEMI] }\end{array}$ & - & $2,940(2,220)$ & - & $6.4(1.6)$ & - & - & - \\
\hline Seyfarth 2008 & 90 & $\begin{array}{l}1,500(360.0- \\
2,460.0)^{*}\end{array}$ & - & - & $78(16)$ & - & $87(18)$ \\
\hline \multicolumn{8}{|c|}{ Observational studies } \\
\hline Maini 2012 & 99 & $60(6-4,320)$ & $2.2(1.1)$ & $2.1(0.2)$ & $83(18)^{\ddagger}$ & $101(20)$ & $89(18)^{\ddagger}$ \\
\hline Sjauw 2009 & 100 & $87.8(50.7)$ & - & - & - & - & - \\
\hline O'Neill 2014 & - & $23.7(3.5-62.7)^{*}$ & $2.33(1.40)$ & $4.4(2.2)^{\S}$ & $67.9(20.7)$ & $94.5(21.3)^{\ddagger}$ & - \\
\hline Alasnag 2011 & 96 & 38 (15) & $3(1)$ & $2.1(0.2)$ & - & - & - \\
\hline Venugopal 2014 & 98 & - & $2(1)$ & - & - & - & - \\
\hline Iliodromitis 2011 & 97.4 & $120.1(45.4)$ & - & - & - & - & - \\
\hline Kovacic 2013 & 99 & $41.7(38.7)$ & $2.5(1.0)$ & - & - & - & - \\
\hline Engstrom 2011 & - & - & - & - & $68(22)$ & - & - \\
\hline Ferreiro 2010 & 96.3 & $90(60-110)^{*}$ & $2.3(1.2)$ & $2.2(0.2)$ & - & - & - \\
\hline Anusionwu 2012 & 100 & $603(1,523)$ & - & - & - & - & - \\
\hline Casassus 2015 & - & $2,130(1,338)$ & $1.8(1.0)$ & - & $67(15)^{+}$ & $82(13)^{+}$ & - \\
\hline Dixon 2009 & 100 & $96(36)$ & $2.4(0.9)$ & $2.2(0.3)$ & $84.5(14.3)^{\ddagger}$ & 89 (14.8) & $76(11.9)^{\ddagger}$ \\
\hline Henriques 2006 & 100 & - & - & - & - & - & - \\
\hline Boudoulas 2012 & - & - & - & - & - & - & - \\
\hline Schwartz 2011 & 100 & - & - & - & - & - & - \\
\hline Burzotta 2008 & - & - & 1.6 & - & - & - & - \\
\hline
\end{tabular}

Abbreviations: SD: standard deviation,

* Estimate reported as median (IQR).

$\dagger$ Estimate report based on 15 patients only.

${ }^{\sharp} \mathrm{p}<0.05$ between mean arterial pressure before and after support. 
$\S$ In table of the O’Neil et. al 2014 study, the mean cardiac output reported for pre-PCI Impella patient while on support was 4.4 and that the standard deviation reported for these patients is 2.2. Mean cardiac output reported in this study is the total cardiac output of the patient while on Impella, including the underlying cardiac output of the patient and the flow rate provided by Impella, whereas in the other studies, only the flow rate provided by Impella is reported.

Table 5. Thirty-day and long term clinical outcomes in controlled studies of high-risk patients using either the Impella device or IABP while undergoing PCI.

\begin{tabular}{|c|c|c|c|c|c|c|c|c|c|c|c|c|c|c|}
\hline \multirow[t]{2}{*}{ Study } & \multicolumn{2}{|l|}{$\mathbf{N}$} & \multicolumn{2}{|c|}{$\begin{array}{l}\text { Lost to } \\
\text { follow-up, n } \\
(\%)\end{array}$} & \multicolumn{2}{|l|}{$\begin{array}{l}\text { All-cause } \\
\text { mortality, } \\
\mathrm{n}(\%) \\
\end{array}$} & \multicolumn{2}{|l|}{$\begin{array}{l}\text { Stroke, } \\
\text { n (\%) }\end{array}$} & \multicolumn{2}{|l|}{$\begin{array}{l}\text { MI, } \\
\text { n (\%) }\end{array}$} & \multicolumn{2}{|l|}{$\begin{array}{l}\text { MACE, } \\
\text { n (\%) }\end{array}$} & \multicolumn{2}{|c|}{$\begin{array}{l}\text { Repeat } \\
\text { revascularization, } \\
\mathrm{n}(\%)\end{array}$} \\
\hline & Imp & IABP & Imp & IABP & Imp & IABP & Imp & IABP & Imp & IABP & Imp & IABP & Imp & IABP \\
\hline \multicolumn{15}{|l|}{ 30-day follow-up } \\
\hline $\mathrm{O}^{\prime}$ Neill $2012^{*}$ & 225 & 223 & 0 & 1 & $17^{\ddagger}(7.6)$ & $13^{\ddagger}(5.9)$ & $0(0)^{\dagger}$ & $\begin{array}{l}4^{\ddagger}(1.8) \\
+\end{array}$ & $\begin{array}{l}31^{\ddagger} \\
(13.8)\end{array}$ & $23^{\ddagger}(10.4)$ & $\begin{array}{l}79^{\ddagger} \\
(35.1)\end{array}$ & $\begin{array}{l}89^{\ddagger} \\
(40.1)\end{array}$ & $3^{\ddagger}(1.3)$ & $9^{\ddagger}(4.1)$ \\
\hline Ouweneel 2016 & 24 & 24 & - & - & $11(46)$ & $12(50)$ & - & - & - & - & - & - & - & - \\
\hline Seyfarth 2008 & 13 & 13 & 0 & 0 & $6(46)^{+}$ & $6(46)^{+}$ & - & - & - & - & - & - & - & - \\
\hline \multicolumn{15}{|l|}{ 3-month follow-up } \\
\hline O'Neill 2012 & 225 & 223 & 1 & 3 & $27^{\ddagger}(12.1)$ & $19^{\ddagger}(8.7)$ & $2^{\ddagger}(0.9)$ & $6^{\ddagger}(2.7)$ & $\begin{array}{l}27^{\ddagger} \\
(12.1)\end{array}$ & $31^{\ddagger}(14.2)$ & $\begin{array}{l}91^{\ddagger} \\
(40.6)\end{array}$ & $\begin{array}{l}108^{\ddagger} \\
(49.3)\end{array}$ & $8^{\ddagger}(3.6)$ & $18^{\ddagger}(7.8)$ \\
\hline $\begin{array}{l}\text { Ouweneel } 2016 \text { ( } 6 \\
\text { months) }\end{array}$ & 24 & 24 & - & - & $12(50)$ & $12(50)$ & $1(4)$ & $1(4)$ & $1(4)$ & $2(8)$ & - & - & - & - \\
\hline $\begin{array}{l}\text { Ouweneel } 2016 \\
\text { [STEMI] }^{\S}\end{array}$ & 12 & 9 & 0 & 0 & $3(26)$ & $1(11)$ & $1(8) \|$ & $0(0)^{11}$ & - & - & $3(26)$ & $3(33)$ & - & - \\
\hline \multicolumn{15}{|c|}{ 12-month follow-up } \\
\hline Boudoulas 2012 & 13 & 62 & - & - & $2(15.3)$ & $16(25.8)$ & - & - & - & - & - & - & - & - \\
\hline Ouweneel 2016 & 12 & 9 & 0 & 0 & $3(26)$ & $1(11)$ & $1(8)^{\prime \prime}$ & $0(0)^{\prime I}$ & - & - & $4(37)$ & $4(47)$ & - & - \\
\hline
\end{tabular}

Abbreviations: Imp: Impella, IABP: intra-aortic balloon pump, MACE: major adverse events, MI: myocardial infarction.

* Reported for intent-to-treat population (ITT). Study also includes pre-protocol.

${ }^{\dagger} \mathrm{p}<0.05$ between groups.

* Event totals calculated from the reported percentages.

${ }^{\S}$ Estimates reported based on 4-month follow-up.

"Estimates reported during the entire clinical course. 
This is the peer reviewed version of the following article: [Ait Ichou, J., Larivée, N., Eisenberg, M.J., Suissa, K., and Filion, K.B. (2017). The effectiveness and safety of the Impella ventricular assist device for high-risk percutaneous coronary interve

Table 6. Thirty-day and long term clinical outcomes in uncontrolled studies of high-risk patients using the Impella device while undergoing PCI.

\begin{tabular}{|c|c|c|c|c|c|c|c|}
\hline Study & $\begin{array}{l}\text { Lost to } \\
\text { follow- } \\
\text { up, } n\end{array}$ & $\begin{array}{l}\text { All-cause } \\
\text { mortality, } \\
\mathrm{n}(\%)\end{array}$ & $\begin{array}{l}\text { Stroke, } \\
\text { n (\%) }\end{array}$ & $\begin{array}{l}\text { MI, } \\
\text { n (\%) }\end{array}$ & $\begin{array}{l}\text { MACE, } \\
\text { n (\%) }\end{array}$ & $\begin{array}{l}\text { Repeat } \\
\text { revascularization } \mathrm{n} \\
(\%)\end{array}$ & $\begin{array}{l}\text { Hematoma } \\
\text { n (\%) }\end{array}$ \\
\hline \multicolumn{8}{|l|}{ 30-day follow-up } \\
\hline Maini 2012 & 0 & $7(4)$ & $1(0.6)$ & $2(1.1)$ & $14(8)$ & $1 *(0.6)$ & - \\
\hline Sjauw 2009 & - & $8(5.5)$ & $1(0.7)$ & $0(0)$ & - & - & - \\
\hline O'Neill 2014 & 9 & $23 *(42.6)$ & - & - & - & - & - \\
\hline Alasnag 2011 & 0 & $3(5)$ & $0(0)$ & $0(0)$ & $3(5)$ & - & $5(8.3)$ \\
\hline Venugopal 2014 & 0 & $8(18)$ & $1(2)$ & $1(2)$ & - & - & - \\
\hline Iliodromitis 2011 & 0 & $1(2.86)$ & $0(0)$ & $\begin{array}{l}21 \\
(63.6)\end{array}$ & - & - & $6(15.8)$ \\
\hline Kovacic 2013 & 0 & $0(0)$ & $0(0)$ & $2(6)$ & - & $0(0)$ & $3(8)$ \\
\hline Engstrom 2011 & 8 & $25(74)$ & - & - & - & - & - \\
\hline Ferreiro 2010 & 0 & $1(3.7)$ & - & $\begin{array}{l}6 \\
(22.2)\end{array}$ & $3(11.1)$ & $0(0)$ & - \\
\hline Anusionwu 2012 & 0 & - & - & - & - & - & $2(8)$ \\
\hline Dixon 2009 & 0 & $2(10)$ & $0(0)$ & $2(10)$ & $4(20)$ & $0(0)$ & $8(40)$ \\
\hline Henriques 2006 & 0 & $4(21)$ & - & - & - & - & - \\
\hline Burzotta 2008 & 0 & $1(10)$ & - & - & $0(0)$ & $=$ & $=$ \\
\hline \multicolumn{8}{|c|}{ 6-month follow-up } \\
\hline Maini 2012 & - & (9) & - & - & - & - & - \\
\hline Casassus 2015 & 0 & (40.9) & - & - & - & $2^{*}(10)$ & - \\
\hline \multicolumn{8}{|c|}{ 12-month follow-up } \\
\hline Maini 2012 & - & $(12)$ & - & - & - & - & - \\
\hline Casassus 2015 & 0 & $10(45.5)$ & - & - & - & - & - \\
\hline Burzotta 2008 & 0 & $1(10)$ & - & - & $3(30)$ & $2(20)$ & - \\
\hline
\end{tabular}

Abbreviations: MACE: major adverse cardiac events, MI: myocardial infarction, PCI: percutaneous coronary intervention.

* Event totals calculated from the reported percentage. 